\title{
Effects of Folic Acid and Magnesium Co-Administration on Blood Glucose Levels in Streptozotocin-Induced Type I Diabetic Wistar Rats
}

\author{
Anthony Donatus Teru Goji ${ }^{1}$, Aliyu Mohammed ${ }^{2}$, Yusuf Tanko ${ }^{2}$ and Mohammed Umaru Kawu ${ }^{3}$ \\ 1. Department of Human Physiology, College of Medical Sciences, Gombe State University, Gombe, Nigeria \\ 2. Department of Human Physiology, Ahmadu Bello University, Zaria, Nigeria \\ 3. Department of Veterinary Physiology, Ahmadu Bello University, Zaria, Nigeria
}

\begin{abstract}
This work was designed to study the effects of FA+ Mg (folic acid and magnesium) co-administration on blood glucose levels of STZ (streptozotocin) induced diabetic rats. Healthy albino rats weighing between $150 \mathrm{~g}$ and $200 \mathrm{~g}$ were used. The rats were randomly allotted into six groups, each containing five albino rats respectively. Five of the groups ( II, III, IV, V and VI) were induced with diabetes by the by i.p. (intraperitoneal) injection of freshly prepared in $0.1 \mathrm{~mol} / \mathrm{L}$ citrate buffered solution (pH 4.5 ) of streptozotocin (Sigma Aldrich, St. Louis, MO, USA) at a dose of $60 \mathrm{mg} / \mathrm{kg}$ body weight. Control (vehicle) rats were injected with equal volume of $0.1 \mathrm{~mol} / \mathrm{L}$ citrate buffer. Four days after STZ injection, diabetes induction was confirmed by measuring fasting blood glucose level in a tail vein blood samples using ACCU-CHEK compact plus glucometer (Roche, France). Rats with glucose level of $200 \mathrm{mg} / \mathrm{dl}$ or higher were considered as diabetic. After the induction of diabetes, the rats were treated using the folic acid and magnesium separately and in combination respectively according to group daily, whereas, the other group (a) was not given any treatment and this served as the normal control, providing a baseline data. Blood samples were collected from the rat tail vein weekly for a period of four weeks. Results obtained from the study showed that FA+ Mg administered conjointly lowered blood glucose levels after 4 weeks of treatment when compared to diabetic control, significantly $(P<0.05)$. The action of the co-administration of folic acid and magnesium on blood glucose in diabetic rats was similar to that of Insulin $(6 \mathrm{IU} / \mathrm{mL})$, a potent hypoglycaemic agent. Oral supplementation of folic acid ( $20 \mathrm{mg} / \mathrm{kg} \mathrm{b.w.} \mathrm{/day)} \mathrm{and} \mathrm{MgCl}_{2}(500 / \mathrm{kg}$ b.w. /day) separately or in combination for 4 weeks of treatment exhibited differential protective response in lowering the blood glucose levels following treatments. It was also found that during combined exposure of folic acid and magnesium, the adverse effects of the diabetes induced by STZ were less pronounced in the group that had FA+ Mg than their individual effects. This suggests the synergistic beneficial effects of folic acid and Magnesium against STZ-induced diabetes in Wistar Rats.
\end{abstract}

Key words: Diabetes, hypoglycemia, folic acid, magnesium, wistar rats.

\section{Introduction}

T1D (Type 1 diabetes) is associated with an increased long-term risk of CVD (cardiovascular disease) originating in Childhood [1]. Major contributory factors are hyperglycemia, hypertension, dyslipidemia, overweight, and tobacco use which are amenable to prevention and treatment [2]. The free radical scavenging properties and possible antioxidant

\footnotetext{
Corresponding author: Anthony Donatus Teru Goji, Ph.D., research field: endocrinology. E-mail: dongoji_4u@yahoo.com.
}

activity of folic acid are reported [3, 4], assessed the effect of FA treatment on T1DM by analyzing the gene expression profile of EPCs (Endothelial progenitor cells) from T1DM patients treated with FA and comparing it to that from healthy controls, and showed that FA normalized a majority of changes in gene expression induced by T1DM (99.6\%), suggesting the therapeutic potential of FA in the treatment of T1DM.

Transplantation therapies for type $1 \mathrm{DM}$ include whole organ transplantation [5], transplantation of isolated islets [6,7] and regeneration therapy [8]. 
Although the transplantation of both a whole organ and isolated islets has been successfully used in the clinical treatment of type 1 DM, a shortage of donors limits the widespread use of this treatment modality. Additionally, the quality of a donor's pancreas is an important criterion for islet isolation [9].

Therefore, regeneration of pancreatic islets is certainly a worthwhile therapeutic goal that would substantially ameliorate diabetes and lessen its complications [10]. An alternative strategy to treat diabetes is the use of various plant extracts and herbal biomolecules, due to their hypoglycemic effects. Detailed investigation of these biomolecules has revealed that some of them cause a regeneration of $\beta$-cells, thus causing a reversal of diabetes in human and non-human subjects [11].

Magnesium is an essential ion involved in glucose homeostasis [12]. It is a co-factor in the glucose transport system of plasma membrane, has an important role in the activity of various enzymes involved in glucose oxidation, may play a role in the release of insulin, and can modulate the mechanism of energy transfer from high energy phosphate bond [13].

\section{Materials and Methods}

Streptozoxocin (Sigma Aldrich Inc.st Louis, MO, USA), Folic acid (Sigma), Magnesium, (Sigma Aldrich Inc.st Louis, MO, USA), Glucose. All other chemicals and drugs were obtained commercially and were of analytical grade.

\subsection{Experimental Animals}

Thirty Wistar rats male weighing between 200 to $250 \mathrm{~g}$ (aged six to eight weeks) were obtained and housed in the animal house unit of the Department of Human Physiology, Ahmadu Bello University, Zaria. The normal standard rat chow and tap water were provided ad libitum during the experiment. Animals were stabilized to acclimatize to animal house environment for one week before commencement of the experiment. The study protocol was approved by the Institutional Animal Ethnic Committee of the University, Ahmadu Bello University, Zaria.

\subsection{Methodology}

\subsubsection{Induction of Diabetes Mellitus}

Diabetes was chemically induced by intraperitoneal (i.p.) injection of freshly prepared in $0.1 \mathrm{~mol} / \mathrm{L}$ citrate buffered solution $(\mathrm{pH} 4.5)$ of streptozotocin (Sigma Aldrich, St. Louis, MO, USA) at a dose of $60 \mathrm{mg} / \mathrm{kg}$ body weight. Control (vehicle) rats were injected with equal volume of $0.1 \mathrm{~mol} / \mathrm{L}$ citrate buffer. Four days after STZ injection, diabetes induction was confirmed by measuring fasting blood glucose level in a tail vein blood samples using ACCU-CHEK compact plus glucometer (Roche, France). Rats with glucose level of $200 \mathrm{mg} / \mathrm{dl}$ or higher were considered as diabetic [14]. Glucose levels of diabetic rats were checked before starting of treatment, so that animals could be homogenously and randomly distributed between the groups.

\subsubsection{Experimental Design}

Normal healthy rats were used as normal control and diabetic-induced rats and were randomly randomly alloted into six groups $(n=5)$ :

Group 1: Normal untrated rats were given normal saline $1 \mathrm{ml} / \mathrm{kg}$ daily orally for 4 weeks

Group 2: Diabetic untreated rats were given Normal saline $1 \mathrm{ml} / \mathrm{kg}$ daily orally for 4 weeks.

Group 3: Diabetic rats were treated with magnesium $500 \mathrm{mg} / \mathrm{kg}$ daily orally for 4 weeks [15].

Group 4: Diabetic rats were treated with folic acid 20 $\mathrm{mg} / \mathrm{kg}$ daily orally 4 weeks [16].

Group 5: Diabetic rats were treated with magnesium $500 \mathrm{mg} / \mathrm{kg}+$ folic $20 \mathrm{mg} / \mathrm{kg}$ acid daily orally for 4 weeks.

Group 6: Diabetic rats were treated with Insulin 6 I.U/kg i.p. daily orally for 4 weeks [14].

\subsubsection{Determination of Blood Glucose Levels}

Blood samples were collected from the rat tail vein weekly for a period of four weeks. Determination of the blood glucose levels will be carried out using 
ACCU-CHEK compact plus glucometer (Roche, France).

\subsection{Statistical Analysis}

All data were expressed as Mean \pm SEM and data were entered and analyzed using statistical package SPSS (version 20) followed by one way ANOVA (analysis of variance) with multiple comparisons. The Tukey's post-hoc test was used to determine difference between groups. Values of $P<0.05$ was considered as statistically significant [17].

\section{Results}

\subsection{Effect of Folic Acid and Magnesium on Blood} Glucose levels

Folic acid and Magnesium co-administration significantly $(P<0.05)$ decreased blood glucose level in treated diabetic rats compared to diabetic control. $\mathrm{FA}+\mathrm{Mg}$ decreased blood sugar from $331 \pm 59.76$ $\mathrm{mg} / \mathrm{dl}$ in diabetic rats to $121 \pm 22.05 \mathrm{mg} / \mathrm{dl}$ after 4 weeks of treatment while the group that had FA alone and $\mathrm{Mg}$ alone lowered same from $305.2 \pm 46.47 \mathrm{mg} / \mathrm{dl}$ in diabetic rats to $217.8 \pm 45.34 \mathrm{mg} / \mathrm{dl}$ after 4 weeks of treatment, respectively. The results compared favourably with that of Insulin, a standard drug (Table 1).

\section{Discusssion}

Type 1 diabetes affects 11-22 million people worldwide, with the number of patients predicted to rise significantly in the future [18]. Type 1 diabetes occurs as a consequence of autoimmune destruction of pancreatic $\beta$-cells, leading to insulin deficiency, a defect that causes hyperglycaemia, polydipsia, polyuria, polyphagia, ketoacidosis and other abnormalities [19]. Type 1 diabetes is fatal without daily insulin administration, and while insulin therapy reduces hyperglycaemia and prevents or delays some type 1 diabetes associated morbidities [20] many people with diabetes only barely maintain the recommended goal for blood glucose control and suffer from chronic diabetic complications [21]. Further, insulin therapy significantly increases the risk of hypoglycaemia, which can be life threatening [22]. As such, despite the profound diabetes-improving effects of insulin therapy, these regimens do not restore adequate metabolic homeostasis and may even lead to serious side effects [23]. Thus, additional antitype 1 diabetes approaches are urgently needed. Here, to evaluate the detailed effectiveness for type 1 diabetes, we investigated the physiological effects of co-administration of Folic acid and Magnesium on STZ-induced type 1 diabetes on blood glucose level, haematological parameters and total plasma protein concentration in STZ-induced type 1 diabetic rats. From results obtained, STZ selectively destroyed the pancreatic beta cells of the rats used causing marked degeneration of the islets of langerhans which lowered insulin secretion with reduction in the rate of conversion of glucose to glycogen. The result of which was the marked increase of sugar level (hyperglycaemia) in the diabetic rats. The present

Table 1 Effect of folic acid and/or magnesium on blood glucose concentration in STZ induced diabetic wistar rats.

\begin{tabular}{llllll}
\hline & Initial & Week 1 & Week 2 & Week 3 & Week 4 \\
\hline Group Normal & $93.2 \pm 3.60$ & $86.4 \pm 3.44$ & $90.6 \pm 3.83$ & $96 \pm 4.43$ & $94.4 \pm 4.12$ \\
Group Diabetic & $329.6 \pm 43.22$ & $435.6 \pm 46.41^{\mathrm{b}}$ & $409.2 \pm 44.50^{\mathrm{b}}$ & $367.6 \pm 19.22^{\mathrm{b}}$ & $355.4 \pm 46.96$ \\
Group FA+ Diabetes & $305.2 \pm 46.47$ & $196.8 \pm 39.30^{\mathrm{a}}$ & $225.2 \pm 29.76^{\mathrm{b}, \mathrm{a}}$ & $238.6 \pm 62.93^{\mathrm{b}, \mathrm{a}}$ & $217.8 \pm 45.34$ \\
Group Mg+Diabetes & $329.4 \pm 9.34$ & $214 \pm 27.23^{\mathrm{a}}$ & $164 \pm 37.70^{\mathrm{a}}$ & $178.6 \pm 29.60^{\mathrm{a}}$ & $182.2 \pm 39.52^{\mathrm{a}}$ \\
Group FA+ Mg+Diabetes & $331 \pm 59.76$ & $193 \pm 25.44^{\mathrm{a}}$ & $161.4 \pm 34.30^{\mathrm{a}}$ & $126.4 \pm 6.12^{\mathrm{a}}$ & $121 \pm 22.05^{\mathrm{a}}$ \\
Group Insulin+Diabetes & $326.4 \pm 53.86$ & $166.4 \pm 36.17^{\mathrm{a}}$ & $120.8 \pm 10.25^{\mathrm{a}}$ & $115 \pm 4.53^{\mathrm{a}}$ & $106.6 \pm 3.65^{\mathrm{a}}$ \\
\hline
\end{tabular}

Note: Values are mean $\pm \mathrm{SEM}, n=5$.

${ }^{\text {a }} P<0.05$ versus diabetic group.

${ }^{\mathrm{b}} P<0.05$ versus normal group. 
findings come in accordance with those obtained by Isamial [24] who reported that, significant increase in blood sugar and decrease in insulin concentrations were recorded in STZ induced diabetic rabbits compared to control rabbits. The same authors reported that, the increased in blood glucose and decreased in insulin concentrations reflect abnormalities in beta cell function induced by STZ.

Results obtained from the study showed that FA+ $\mathrm{Mg}$ administered conjointly, significantly $(P<0.05)$ lowered blood glucose levels after 4 weeks of treatment when compared to diabetic control. The action of the co-administration of folic acid and magnesium on blood glucose in diabetic rats is similar to that of Insulin $(6 \mathrm{IU} / \mathrm{ml})$, a potent hypoglycaemic agent. The co-administration may have achieved this hypoglycaemic property via increased glucokinase gene expression and the resultant increase in glucokinsae activity in the liver, increased peripheral utilization of glucose, or inhibition of endogenous glucose production [25].

Fang assessed the effect of FA treatment on T1DM by analyzing the gene expression profile of EPCs (Endothelial progenitor cells) from T1DM patients treated with FA and comparing it to that from healthy controls, and showed that FA normalized a majority of changes in gene expression induced by T1DM (99.6\%), suggesting the therapeutic potential of FA in the treatment of T1DM [4]. Magnesium is an essential ion involved in glucose homeostasis [12]. It is a co-factor in the glucose transport system of plasma membrane, has an important role in the activity of various enzymes involved in glucose oxidation, may play a role in the release of insulin, and can modulate the mechanism of energy transfer from high energy phosphate bond [13]. These observations further substantiate synergistic protective effect of folic acid and magnesium in STZ-induced diabetes in rats.

\section{Conclusion}

In conclusion, the data obtained in this study suggest that $\mathrm{FA}+\mathrm{Mg}$ combination may be an effective anti-hypoglycemic agent via its ability to increased level of GCK activity in FA+ Mg treated diabetic rats. So it may be useful for preventing or delaying the development of diabetes and its complications.

\section{Acknowledgement}

The authors wish to thank Mallam Ya'u Bello casual staff of the Department of Human Physiology, $\mathrm{ABU}$, and Zaria for the care of the experimental animals throughout the period of this research work.

\section{References}

[1] Giannini, C., Mohn, A., Chiarelli, F., and Kelnar, C. J. 2011. "Macrovascular Angiopathy in Children and Adolescents with Type 1 Diabetes." Diabetes Metab. Res. Rev. 27 (5): 436-60.

[2] Dost, A., Klinkert, C., Kapellen, T., Lemmer, A., Naeke, A., and Grabert M. 2008. "Arterial Hypertension Determined by Ambulatory Blood Pressure Profile. Contribution to Microalbuminuria Risk in a Multicenter Investigation in 2105 Children and Adolescents with Type 1 Diabetes." Diabetes Care 31 (4): 720-5.

[3] Ravi, J., Adhikari, S., Patro, B. S., Phattopadhyay, S., and Mukherjee, T. 2001. "Free Radical Scavenging Behavior of Folic Acid: Evidence for Possible Antioxidant Activity.' Free Radical Biology \& Medicine 30 (12): 1390-9.

[4] Fang, D. N., He, X. D., Li, X. H., Jia, H., Li, P. Y., Lu, Q., Quan, Q., and Wang, Q. L. 2014. "Bioinformatic Analysis of Endothelial Progenitor Cells Exposed to Folic Acid in Type 1 Diabetes Mellitus." Genetics and Molecular Research 13 (1): 1-10.

[5] Larsen, J. L. 2004. "Pancreas Transplantation: Indications and Consequences.” Endocr. Rev. 25 (6): 919-46.

[6] Shapiro, A. M., Lakey, J. R., Ryan, E. A., Korbutt, G. S., Toth, E., Warnock, G. L., Kneteman, N. M., and Rajotte, R. V. 2000. "Islet Transplantation in Seven Patients with Type 1 Diabetes Mellitus Using a Glucocorticoid-Free Immunosuppressive Regimen.” N. Eng. J. Med. 343 (4): 230-8.

[7] Ryan, E. A., Lakey, J. R., Rajotte, R. V., Korbutt, G. S., Kin, T., Imes, S., Rabinovitch, A., Elliott, J. F., Bigam, D., Kneteman, N. M., Warnock, G. L., Larsen, I., and Shapiro, A. M. 2001. "Clinical Outcomes and Insulin Secretion after Islet Transplantation with the Edmonton Protocol." Diabetes 50 (4): 710-9.

[8] Yamaoka, T. 2002. "Regeneration Therapy of Pancreatic Beta Cells: Towards a Cure for Diabetes?" Biochem. 


\section{Streptozotocin-Induced Type I Diabetic Wistar Rats}

Biophys. Res. Commun. 296 (5): 1039-43.

[9] Matsumoto, S., Noguchi, H., Hatanaka, N., Shimoda, M., Kobayashi, N., Jackson, A., Onaca, N., Naziruddin, B., and Levy, M. F. 2009. "Estimation of Donor Usability for Islet Transplantation in the United States with the Kyoto Islet Isolation Method." Cell Transplant 18 (5): 549-56.

[10] Risbud, M. V., and Bhonde, R. R. 2002. "Models of Pancreatic Regeneration in Diabetes." Diab. Res. Clin. Pract. 58 (3): 155-65.

[11] Xiu, L. M., Miura, A. B., Yamamoto, K., Kobayashi, T., Song, Q. H., Kitamura, H., and Cyong, J. C. 2001. "Pancreatic Islet Regeneration by Ephedrine in Mice with Streptozotocin-Induced Diabetes." Am. J. Chin. Med. 29 (3-4): 493-500.

[12] Nadler, J. L., and Rude, R. K. 1995. "Disorders of Magnesium Metabolism.” Endocrinol. Metab. Clin. North. Am. 24 (2): 623-41.

[13] Yajnik, C. S., Smith, R. F., Hockaday, T. D. R., and Ward, H. I. 1984. "Fasting Plasma Magnesium Concentrations and Glucose Disposal in Diabetes.” Br. Med. J. 288 (6423): 1032-4.

[14] Stanley, P., Mainzen, P., and Venugopal, M. P. 2001. "Antioxidant Action of Tinospora, Cordifolia Root Extract in Alloxan-Induced Diabetic Rats." Biotechnol. Appl. Biochem. 15: 20-31.

[15] Hfaiedh, N., Murat, J. C., and Elfeki, A. 2013. "Diabetes-Induced Damages in Rat Kidney and Brain Protective Effects of Natural Antioxidants." J. Nutr. Food Sci. 3:4.

[16] Paget, G. E., and Barnes, J. M. 1964. "Toxicity Test.” In Evaluation of Drug Activities Pharmacometrics, edited by Laurence, D. R., and Bacharach, A. L. London and New York: Academic Press, 134-66.

[17] Duncan, R. C., Knapp. R. G., and Miller, M. C. 1977. "Test of Hypotheses in Population Means" In Introductory
Biostatistics for Health Science, N.Y.: John Wiley and Son Inc, 71-6.

[18] Borchers, A. T. 2010. "The Geoepidemiology of Systemic Lupus Erythematosus." Autoimmun Rev. 9 (5): 277-87.

[19] Daneman, D. 2006. "Type 1 Diabetes." Lancet 367 (9513): 847-58.

[20] The Diabetes Control and Complications Trial/Epidemiology of Diabetes Interventions and Complications (DCCT/EDIC) Study Research Group. 2005. "Intensive Diabetes Treatment and Cardiovascular Disease in Patients with Type 1 Diabetes." N. Engl. J. Med. 353 (25): 2643-53.

[21] Bluestone, J. A., Herold, K., and Eisenbarth, G. 2010. "Genetics, Pathogenesis and Clinical Interventions in Type 1 Diabetes." Nature 464 (7293): 1293-300.

[22] Cryer, P. E. 2009. "Preventing Hypoglycaemia: What is the Appropriate Glucose Alert Value?" Diabetologia. 52 (1): 35-7.

[23] Atsuo, T., Eiji, K., Masanori, Y., Daisuke, Y., Rumi, K., Yuka, H., Toshiyuki, T., Masakazu, I., Qun, L., Hiroshi, T., Yoshinori, K., Atsushi, N., Masao, S., and Masayuki, S. 2014. "Effects of Sodium-Glucose Cotransporter 2 Selective Inhibitor Ipragliflozin on Hyperglycaemia, Oxidative Stress, Inflammation and Liver Injury in Streptozotocin-Induced Type 1 Diabetic Rats." Journal of Pharmacy and Pharmacology 66 (7): 975-87.

[24] Isamial, I. A. G., and Kadry, M. S. 2012. "Olive Leaves Extract Restores Antioxidant Perturbation in Red Blood Cells Hemolysaye in STZ Induced Diabetic Rats." World Academy of Science, Engineering and Technology 6: 4-29.

[25] Tura, F., Anna, P., Efren, R., Fatima, B., and Alfons, V. 1996. "Correction of Diabetic Alterations by Glucokinase." Proc. Natl. Acad. Sci. USA 93 (14): 7225-30. 